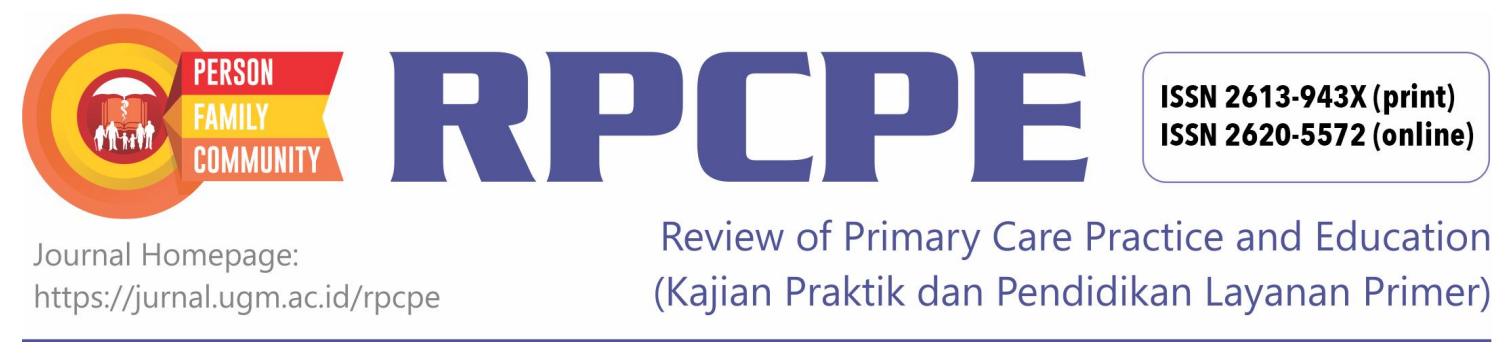

\title{
Stress Level Relationship with Prediabetes Events in Sleman Yogyakarta
}

\author{
Novi Husmarini ${ }^{1}$, Wahyudi Istiono ${ }^{2}$, Ronny Tri Wirasto ${ }^{3}$ \\ ${ }^{1}$ Pratama Clinic Poltekkes Kemenkes Yogyakarta; Indonesia \\ ${ }^{2}$ Department of Family and Community Medicine; Faculty of Medicine, Public Health and Nursing; Universitas Gadjah Mada; \\ Indonesia \\ ${ }^{3}$ Department of Internal Medicine RSUP Dr. Sardjito Yogyakarta; Indonesia \\ Corresponding Author: \\ Novi Kusmarini: Pratama Clinic Poltekkes Kemenkes Yogyakarta, Jl. Gadingsari Kajor Nogotirto Gamping Sleman Yogyakarta \\ - 55293, Indonesia \\ E-mail: husmarininovi@yahoo.com \\ To cite this article: \\ Husmarini N, Istiono W, Wirasto RT. Stress Level Relationship with Prediabetes Events in Sleman Yogyakarta. Rev Prim Care Prac \\ and Educ. 2019; 2(2): 76-80.
}

\begin{abstract}
Background: Prediabetes prevalence in the world is increasing, and is estimated to reach $20.6 \%$ in 2025. Prediabetes prevalencein Indonesia is almost double the prevalence of diabetes mellitus. Prediabetes often does not cause symptoms but has already started to occur with both microvascular and macrovascular complications in some patients. Stress is a disorder of the body and mind causedby changes and demands of life. Stress that occurs at this time, is part of the effects of modern life, and cannot be avoided, both in the work environment, and school, as well as family and society. In the state of stress the secretion of the hormone cortisol increases, which pushes the pancreas to produce insulin, so that there is an increase in blood sugar levels. Objective: This study was conducted with the aim to know the relationship of stress level in prediabetes sufferer and know the description of the stress level of prediabetes patient in Sleman Yogyakarta area. Methods: This research was a quantitative study with a cross-sectional design, done in the working area of the first health facility of Sleman Regency, Yogyakarta. Sampling was done by simple random sampling, and research subjects were patients in the working area of Puskesmas in Sleman that fulfilled inclusion and exclusion criteria then examined. Results: The mean age of the study subjects was 46.7 years (SD 11.02). The distribution of subjects of the study was 121 females (78.1\%), and 34 males (21.9\%). Based on a total of 155 respondents, 19 respondents (12.3\%) were diagnosed with prediabetes based on TTGO results and 136 people (87.7\%) had normal TTGO results. Based on a total of 155 respondents, 69 respondents $(47.1 \%)$ had a mild stress level, 80 respondents $(49 \%)$ moderate stress level and 6 respondents $(3.9 \%)$ had severe stress level. The result of thebivariate analysis showed that there was no correlation between stress level and prediabetes occurrence in Sleman Yogyakarta and $p=0.825$ (CI 95\%: 0.879-1.67) was not statistically significant ( $p>0.05$ ). Prediabetes prevalence was $12.3 \%$ in the study population. Conclusion: There was no correlation between stress levels with the occurrence of prediabetes in Sleman Yogyakarta area. Stress levels were moderate among prediabetes sufferers more than mild and severe stress levels.
\end{abstract}

Keywords: Prediabetes, Stress Level, Sleman Yogyakarta

\section{INTRODUCTION}

Prediabetes is also called Impaired Glucose Tolerance or Disturbed Blood Glucose, which is one of the degenerative diseases in which a person has blood glucose levels higher than normal values but has not reached the condition of diabetes and there is no sign or no symptom at all ${ }^{1}$. It is estimated that worldwide there were $8 \%$ of prediabetes sufferers in 2011, and this is expected to increase to $20.6 \%$ by $2025^{2}$. Research conducted by Soewondo and Pramono $^{3}$, using secondary Riskesdas 2007 data on 33 provinces shows prediabetes prevalence in Indonesia of $10 \%$, while the prevalence of Diabetes Mellitus was only $5.7 \%$. This indicates that the prevalence of prediabetes in Indonesia is almost double the prevalence of diabetes mellitus.

Prediabetes often does not cause symptoms, so the patient is not already aware of their condition, which has started to occur with both microvascular and macrovascular complications in some patients ${ }^{4}$. The earliest complication that occurs in prediabetes patients is neuropathy ${ }^{5}$. In the course of the illness, one-third of people with prediabetes will become Diabetes Mellitus, one-third will remain as prediabetes and another third will be normoglycemia ${ }^{6}$. Prediabetes risk factors are similar to risk factors for diabetes mellitus and include heredity, poor diet, and 
lack of physical activity, aging, medication, smoking, and stress $^{7}$.

Stress is a disorder of the body and mind caused by changes and demands of life, are influenced by the environment and the appearance of individuals within the environment, and can have a total impact on individuals, on both physical, intellectual, and psychological aspects, as well as social and spiritual, which can threaten physiological balance ${ }^{8}$. Stress that occurs at this time, is part of the effects of modern life, and cannot be avoided, both in the work environment, and school, as well as the family and society. Some modern lifestyles that cause stress include work, where today many people whose lives are very busy with work, they leave early in the morning and just go home at night, because they have a certain target goal, not to mention facing traffic congestion when leaving and going home from the office. They are also used to doing many activities at a time, as well as the demands of a highly competitive job world that also can cause stress. In addition, family life in the present is also not free from stress, when family members (father, mother, and children) do not have enough time to be together, many mothers who have multiple roles as housewives and as workers who sometimes make children isolated, when children lack love, and because they do not have time to prepare food at home, family members are forced to buy food outside, and often buy fast food that is less good for their health ${ }^{3}$.

In the state of stress the secretion of the hormone cortisol increases, which pushes the pancreas to produce insulin, then hyperinsulinemia occurs so that there is an increase in blood sugar levels ${ }^{9}$. In addition, increased secretion of the hormone cortisol also causes increased glucose production by the liver and disrupts the use of glucose in muscle tissue and increases fat by fighting against the work of insulin ${ }^{10}$.

\section{METHODS}

This research was a quantitative study with a crosssectional design. The population of the research was the residents of Sleman Yogyakarta. The subjects of the study were the patients who were in the working area of Puskesmas Sleman, in the Yogyakarta District with the following inclusion and exclusion criteria and a sample size of 155. Selection of research samples was done by simple random sampling method. The inclusion criteria were: 25-65 years old, live in Sleman or live in the Sleman area and are willing to be respondents by signing the informed consent form. While the exclusion criteria were: aged less than 25 years and over 65 years, pregnant women, previously diagnosed DM, diagnosed DM on blood tests, and did not sign the informed consent form. The diagnosis of prediabetes was done through 2 stages, namely by examining fasting blood glucose and oral glucose tolerance test (TTGO). Blood sampling was done with venous blood which was then examined in the Clinical Pathology laboratory. Measurement of stress levels used the Perceived stress scale (PSS) questionnaire, where stress levels were categorized into mild, moderate and severe stress levels. This research consisted of two variables namely the dependent variable (bound) which was prediabetes and the independent variable (free) which was stress level. Analysis of research results used univariate analysis to give a description of the characteristics of each data collected, and bivariate analysis was conducted to determine the relationship between the dependent variable and independent variable. The statistical test used was the Chi-Square test.

\section{RESULTS}

After giving the explanation of the research procedure and signing the informed consent, we enlisted 180

Table 1. Distribution of Research Subjects by Characteristics

\begin{tabular}{lll}
\hline \multicolumn{1}{c}{ Variables } & \multicolumn{1}{c}{ Frequency } & Percentage* $^{*}$ \\
\hline Gender & 34 & $21.9 \%$ \\
Men & 121 & $78.1 \%$ \\
$\quad$ Women & & \\
Age & 46.7 years old (SD $\pm 11,02)$ & \\
Average and SD & 67 & $43.2 \%$ \\
Age $<45$ years old & 88 & $56.8 \%$ \\
Age $\geq 45$ years old & & \\
Level of education & 15 & $9.7 \%$ \\
No school & 20 & $12.9 \%$ \\
SD or equivalent & 31 & $20 \%$ \\
SMP or equivalent & 56 & $36 \%$ \\
SMA or equivalent & 10 & $6.5 \%$ \\
Diploma or equivalent & 18 & $11.6 \%$ \\
S1 or equivalent & 5 & $3.2 \%$ \\
Postgraduate or equivalent & & \\
Work & 77 & $49.7 \%$ \\
Housewife & 45 & $29.1 \%$ \\
Private / Civil Servants & 33 & $21.2 \%$ \\
Etc. & & \\
Stress level & 69 & $47.1 \%$ \\
Light & 80 & $49.0 \%$ \\
Medium & 6 & $3.9 \%$ \\
$\quad$ Weight & & $87.7 \%$ \\
Prediabetes based on TTG & 136 & $12.3 \%$ \\
Normal & 19 & \\
Prediabetes & & \\
\hline
\end{tabular}


people who were willing to be the subjects of research. However, based on profound anamnesis and blood glucose examination results, 25 people were excluded from the study, bringing the total subjects to 155 respondents. The results of the univariate analysis included a description of the distribution of respondent's characteristics of gender, age, education level, occupation, stress level, and sugar content.

Table 1 shows the mean age of the study subjects was 46.7 years (SD 11.02). There were more subjects with age $\geq 45$ years older than the age of fewer than 45 years. The dominant distribution of female subjects was $78.1 \%$ compared to men as much as $21.9 \%$. The highest level of education was SMA or equivalent as much as $36 \%$, while almost half worked as a housewife which was $49.7 \%$. Based on a total of 155 respondents, 19 respondents (12.3\%) were diagnosed with prediabetes based on TTGO results and 136 people $(87.7 \%)$ had normal TTGO results. Based on a total of 155 responders, moderate stress levels were most commonly experienced by respondents compared with mild and severe stress levels

The result of bivariate analysis in Table 2 shows data results which were analyzed using Fisher Exact statistic test. The results of the tests show that there was no correlation of stress level with prediabetes occurrence in Sleman Yogyakarta region, and $p=0.825$ (CI 95\%: 0.8791.67) was not statistically significant $(p>0.05)$, where the Confidence Interval passed the value of 1 .

Table 2. The relationship of Stress Level with Prediabetes Occurrence

\begin{tabular}{lll}
\hline Prediabetes Stress Level & \multicolumn{2}{l}{ Prediabetes Stress Level } \\
\cline { 2 - 3 } & Yes No & Yes No \\
\hline Weight & $2(12 \%)$ & $4(4 \%)$ \\
Medium & $10(52 \%)$ & $70(51 \%)$ \\
Light & $7(36 \%)$ & $62(45 \%)$ \\
\hline
\end{tabular}

$\mathrm{Chi}^{2} p=0.250$ (CI 95\%: 0.901-1.889), Fisher Exact $p=0.825$ (CI 95\%: 0.879-1.67)

Table 2 also shows an overview of prediabetes and nonprediabetes stress levels, where prediabetes found the most common stress level was moderate stress $(52 \%)$ compared with mild and severe stress levels. In non-prediabetes the same results were also obtained, namely, the most stress was the level of moderate stress (51\%) compared to mild and severe stress levels.

The result of bivariate analysis in Table 3 shows Fisher Exact test was used to find any correlation between age and prediabetes occurrence. The result showed no correlation between age and prediabetes event in Sleman Yogyakarta and $p=0.100(95 \%$ CI: $0.988-2.117)$ was not statistically significant $(p>0.05)$ where the Confidence Interval value passed the value of 1 .

Table 3 also shows that respondents older than 45 years $(12.5 \%)$ are more likely to experience prediabetes compared to those with age less than 45 years. The age of fewer than 45 years of pre-diabetes tendency was then compared to age over 45 years.

Table 3. Age Relationships with Prediabetes Occurrences

\begin{tabular}{lll}
\hline Age of Prediabetes & \multicolumn{2}{l}{ Age of Prediabetes } \\
\cline { 2 - 3 } & Yes No & Yes No \\
\hline Age $<45$ years old & $8(11.9 \%)$ & $59(89 \%)$ \\
Age $\geq 45$ years old & $11(12.5 \%)$ & $77(87,5 \%)$ \\
\hline
\end{tabular}

$\mathrm{Chi}^{2} p=0.916$ (CI 95\%: 0.726-1.937), Fisher Exact $p=0.100$ (CI 95\%: 0.988-2.117)

\section{DISCUSSION}

In this study, the prevalence of prediabetes aged 25-65 years was $12.3 \%$, and this number was higher than the prevalence rate found in Soewondo and Pramono ${ }^{3}$ studyon the prevalence of prediabetes in Indonesia using secondary Riskesdas 2007 data in 33 provinces which had a prevalence of prediabetes in Indonesia of $10 \%$. The results of this study were also higher than the prevalence of prediabetes in the DIY region of $11.2 \%$ (prevalence of prediabetes predicted by prevalence ratio prediabetes doubled prevalence of DM, taken from the prevalence of DM diagnosed by doctors for DIY with a total prevalence of $5.6 \%$ ). A high prevalence rate is a matter of serious concern because diabetic patients are often unaware of the presence of the disease. Even when diagnosed, more than half of the patients had microvascular complications. Therefore, it is wise if diabetes can be prevented and detected when the patient is experiencing prediabetes ${ }^{11}$.
This study shows that the highest prevalence of prediabetes occurs in late adult age ( $\geq 45$ years) which was $12.5 \%$. This finding is in line with the Soewondo and Pramono ${ }^{3}$ studythat showed getting older increases the risk for developing prediabetes. The age-related United States Preventive Services Task Force (USPSTF) guidelines recommend screening or screening prediabetes at the age of over 45 years periodically every 3 years. This recommendation is also included in the consensus on the prevention and treatment of type $2 \mathrm{DMC}$, which is recommended for age screening $>45$ years if one does not have the classic symptoms of $\mathrm{DM}^{12}$. Physiologically at the age of more than 30 years, there will be a fasting blood glucose rise of about 1-2 $\mathrm{mg} / \mathrm{dl}$ per year and blood glucose after eating about 5.6 to $13 \mathrm{mg}$ per year ${ }^{13}$. Whereas in elderly prediabetes can occur at the age of 60-79 years ${ }^{14}$. Patients with age ranging from 40 years are susceptible to DM although not excluding the possibility of occurring at 
age below 40 years. This pattern happens because most people experience physiologic decline that drastically decreases rapidly at the age of 40 years. This decrease will lead to a decrease in the function of the pancreas to produce insulin ${ }^{15}$.

The result of the bivariate analysis showed that there was no correlation between stress level and prediabetes occurrence in Sleman, Yogyakarta with $p=0.825$ (CI 95\%: 0.879-1.67), which was not statistically significant $(p>0.05)$. This finding is in line with William's study ${ }^{16}$ that found there is no perceived stress relationship with prediabetes events in Australia. It is possible that there are several other contributing factors and pathophysiological processes of stress affecting glucose levels in an acute and inconsistent manner. In addition, some confounding factors are also potentially leading to increased blood glucose intolerance such as low energy levels and health status, and physical inactivity ${ }^{17}$. Heikes et al. ${ }^{18}$ argued that the three main factors that contribute to the pathogenesis of prediabetes are diet, physical activity, and inherited genes. Some other conditions that can be related to what is eaten as well as an activity are increased blood pressure and heart disease. Result of statistic test of patient's blood glucose level compared with stress level concluded that there was no difference between the three categorical stress level in the research subjects with $p=0.954(p>0.005)$. This finding may also be influenced by other factors such as drug consumption which may also affect the condition of prediabetes such as steroid tablets, and treatment for schizophrenia and AIDS.

The results of this study are not in line with the results of research Puustinen et al. in $2011^{19}$ which indicated that there is a relationship of psychological stress with the incidence of prediabetes after the adjustment of other factors, i.e. age gender, sociodemographic, and health behavior. Similar results were also obtained in the Wisnatul Izzati and Nirmala ${ }^{20}$ studies conducted in Bukittinggi in 2015, which had results indicating a significant relationship between stress and blood sugar levels.

In the Suwondo and Pramono ${ }^{3}$ study, there are 8 risk factors associated with pre-diabetes events. These factors include male sex, age greater than 58 years, high socioeconomic status, low level of education, hypertension, obesity, central obesity, and smoking become risk factors in prediabetes patients. In addition, several factors that may cause no relationship between stress levels and the incidence of prediabetes in this study, were among others, respondents' perceptions of stress, respondent's stress coping, duration of stress experienced, and other predominant risk factors for prediabetes, among others, hypertension, central obesity, lack of physical activity and obesity. These risk factors can also simultaneously trigger the emergence of prediabetes.

Limitations in this study include the fact that most of the respondents were women, (Selection bias), and this is possible because the measurement was done during working hours, so many men were the artwork. Improper subject selection will affect the result because it is not an accurate representative or true representative of the population. This fact can be seen from the unequal distribution of sex where most of the women who are not working are housewives. Another limitation of this recall is that it occurs when the interviewee has to answer the questionnaire of the stress level in accordance with his / her retrospective memory so that the accuracy of the answer depends on the respondent's ability and the willingness of the respondent to answer truthfully. Recall biases can result in misclassification due to the possibility of the subjects' improperly estimating stress levels. Prevalence of high prediabetes in Sleman region needs to get special attention especially by primary service physicians who should be more vigorous doing the promotive and preventive effort, so it is expected prediabetes patients not become diagnosed with Diabetes Mellitus. It is necessary to conduct further research using a cohort method with sufficient time to be able to see and follow the research directly, with larger sample size and more structured sampling method so that distribution of other factors that can influence the incidence of prediabetes like the proportion of sex of research subject can be more equally distributed

\section{CONCLUSION}

From the results of the study, we concluded there is no correlation of stress level with the occurrence of prediabetes in Sleman Yogyakarta. The description of stress level in prediabetes sufferers in Sleman Yogyakarta region was more dominated by moderate stress level than mild and severe stress level. Prediabetes prevalence in Sleman District was higher than the prevalence found in Indonesia and D.I.Y.

\section{Ethical Approval and Informed consent}

This study had obtained a research permit from the Medical and Health Research Ethics Committee (MHREC) Faculty of Medicine, Public Health and Nursing, Universitas Gajah Mada with No Ref: KE/FK/0017/EC/2018. If the respondent was willing to participate, and had read and understood the information contained in the information sheet, then the respondent was required to sign the informed consent form. All information relating to the identity of the study subjects will be kept confidential and was only known by the researcher.

\section{Funding}

Personal Fund

\section{Data and Material Availability}

For readers who want to access data and materials can contact the author via email husmarininovi@yahoo.com

\section{Conflict of Interest \\ None}

\section{REFERENCES}

1. American Diabetes Association. Diagnosis and classification of diabetes mellitus. Diabetes Care. 2013 Jan 1;36(Supplement 1):S67-74.

2. Atlas D. International diabetes federation. IDF Diabetes Atlas, 7th edn. Brussels, Belgium: International Diabetes Federation. 2015.

3. Soewondo P, Pramono LA. Prevalence, characteristics, and predictors of pre-diabetes in Indonesia. Medical Journal of Indonesia. 2011 Nov 1;20(4):283-94. 
4. Rydén L, Standl E, Bartnik M, Van den Berghe G, Betteridge J, De Boer MJ, et al. Guidelines on diabetes, pre-diabetes, and cardiovascular diseases: executive summary: The Task Force on Diabetes and Cardiovascular Diseases of the European Society of Cardiology (ESC) and of the European Association for the Study of Diabetes (EASD). European heart journal. 2007 Jan 1;28(1):88-136.

5. Dyck PJ, Clark VM, Overland CJ, Davies JL, Pach JM, Dyck PJ, et al. Impaired glycemia and diabetic polyneuropathy: the OC IG Survey. Diabetes Care. 2012 Mar 1;35(3):584-91.

6. Manaf A. Prediabetes. Available from: http://repository.unand. ac.id/89/1/Pre_Diabetes.pdf. Date. 2010; 20.

7. Soegondo S, Soewondo P, Subekti I. Management of integrated diabetes mellitus. Jakarta: Balai Penerbit FKUI. 2009.

8. Rasmun NM, Kep M. Stress, koping and adaptation. Jakarta: CV Sagung Seto. 2004.

9. Lingga L. Healthy and cured with fat. Bogor: Grafika Mardi Yuana. 2012.

10. Muflihatin SK. Relationship between stress levels and blood glucose level of type 2 diabetes mellitus patients in Abdul Wahab Hospital Syahranie Samarinda. Jurnal Ilmu Kesehatan. 2015Nov 15;3(1).

11. Selvin E, Lazo M, Chen Y, Shen L, Rubin J, McEvoy JW, et al. Diabetes mellitus, prediabetes, and incidence of subclinical myocardial damage. Circulation. 2014 Oct 14;130(16):1374-82.

12. Indonesia PE. Consensus on the management and prevention of type 2 diabetes mellitus in Indonesia. Jakarta: PB Perkeni. 2011:1-2.

13. Shaw JE, Sicree RA, Zimmet PZ. Global estimates of the prevalence of diabetes for 2010 and 2030. Diabetes Research and Clinical Practice. 2010 Jan 1;87(1):4-14.

14. Tamayo T, Schipf S, Meisinger C, Schunk M, Maier W, Herder C, et al. Regional differences of undiagnosed type 2 diabetes and prediabetes prevalence are not explained by known risk factors. PloS One. 2014 Nov 17;9(11):e113154.

15. Ifan PS, Wahiduddin DS. Risk factors for prediabetes / gestational diabetes mellitus at RSIA Sitti Khadijah I Makassar City [Skripsi]. Makassar: Universitas Hasanuddin. 2013.

16. Williams ED, Magliano DJ, Tapp RJ, Oldenburg BF, Shaw JE. Psychosocial stress predicts abnormal glucose metabolism: the Australian Diabetes, Obesity and Lifestyle (AusDiab) study. Annals of Behavioral Medicine. 2013 Feb 7;46(1):62-72.

17. Mommersteeg PM, Herr R, Zijlstra WP, Schneider S, Pouwer F. Higher levels of psychological distress are associated with a higher risk of incident diabetes during 18 year follow-up: results from the British household panel survey. BMC Public Health. 2012 Dec;12(1):1109.

18. Heikes KE, Eddy DM, Arondekar B, Schlessinger L. Diabetes Risk Calculator: A simple tool for detecting undiagnosed diabetes and pre-diabetes. Diabetes care. 2008 May 1;31(5):1040-5.

19. Puustinen PJ, Koponen H, Kautiainen H, Mäntyselkä P, Vanhala M. Psychological distress predicts the development of the metabolic syndrome: a prospective population-based study. Psychosomatic Medicine. 2011 Feb 1;73(2):158-65.

20. Izzati W. Relationship between stress levels and increased blood sugar levels in patients with diabetes mellitus in the working area of the urban health center Rasimah Ahmad Bukittinggi in 2015. 'Afiyah. 2015 Jul 1;2(2). 